\title{
Determining Polychlorinated Biphenyls in Soil Using Accelerated Solvent Extraction (ASE)
}

\author{
Iwona Krzemień-Konieczka, Bogusław Buszewski* \\ Department of Environmental Chemistry and Bioanalytics, Faculty of Chemistry, \\ Nicolaus Copernicus University, Gagarin 7, 87-100 Torun, Poland
}

Received: April 2, 2015

Accepted: May 26, 2015

\begin{abstract}
Contamination of the environment with compounds belonging to the persistent organic pollutants (POPs) group constitutes a global problem. According to the Stockholm Convention adopted in 2001, much effort should be put into the minimisation of its presence not only in soil, water, and residues, but also in living organisms where these compounds are accumulated. As a consequence of research conducted in the area of environmental matrices involving wide ranges of chemical compounds, a growing demand for various certified reference materials has been observed. This study was focused on finding the most efficient extraction conditions for six polychlorinated biphenyl congeners: Nos. 28, 52, 101, 138, 153, and 180, with the accelerated solvent extraction (ASE) method and with the use of CRM963 manufactured by RTC. Analyte recovery was examined by the application of the following solvents: hexane, hexane/acetone, and acetone/ dichloromethane at $150^{\circ} \mathrm{C}$ and $170^{\circ} \mathrm{C}$. The best recovery $(88.5-106 \%)$ and the lowest standard deviation $(2.1-5.7 \%)$ values were obtained for hexane at $170^{\circ} \mathrm{C}$. The method was further employed to determine the homogeneity and stability of soil being the candidate for CRM. Moisture and organic carbon content in both the CRM963 as well as the soil examined were determined.
\end{abstract}

Keywords: polychlorinated biphenyls, soil, certified reference materials, gas chromatography, accelerated solvent extraction

\section{Introduction}

Polychlorinated biphenyls (PCBs) belong to the group of persistent organic pollutants (POPs). The POPs are chemical substances that exhibit certain toxic properties which, in contrast to other contaminants, are degradationresistant. The POPs are particularly harmful to humans and the environment. They undergo bioaccumulation in living organisms and distribution by air, water, and migratory species; they also get accumulated in terrestrial and aquatic ecosystems. POP-caused contamination is a transnational problem and therefore requires international cooperation and actions. PCBs are classified to this group due to the properties they present, e.g. high thermal conductivity,

*e-mail: bbusz@chem.umk.pl intermediate vapour pressure, stability at high temperatures, and resistance to acids and bases. In the 1970s, owing to the above-mentioned properties, PCBs were commonly used in industry. Among others, their applications involved the production of condensers, transformers, printing ink, or plastics. The manufacture and use of those products resulted in the problem of waste disposal, and thus environmental contamination. The contamination of water, soil, and residue with PBCs as well as their tendency to bioaccumulate in living organisms constitutes a problem serious enough to result in the reduction of their industrial application as a result of the Stockholm Convent adopted in 2001, which issued limitations to the POPs applications for industrial purposes. Despite the reduction of the PCB application, the problem of environmental contamination still exists [1-3]. 
A significant number of studies currently carried out deals with environmental contamination with compounds of the POPs group. To perform an analysis that gives reliable results, certified materials (CRM) are used in order to check and validate the examination procedure, measuring equipment calibration, and to provide internal and external control over laboratories. The CRMs ensure homogeneity, stability, and well-known physical and chemical properties $[4,5]$.

Extraction using the accelerated solvent extractor (ASE) is a commonly employed method of separating numerous compounds from the POPs group, e.g. the polycyclic aromatic hydrocarbons (PAH), pesticides, and PCBs from various environmental matrices. The method is often used due to the use of small amounts of solvents, small weighed amounts, short analysis time, and satisfactory repeatability [6-10].

Our research was aimed at finding and validating the most efficient conditions for the method of extracting six PCB congeners with the use of a commercial reference material. It also focused on determining those compounds' content, homogeneity, and stability in natural soil, which is a candidate for the certified material of soil used in PBC determination.

\section{Experimental Procedures}

\section{Experimental Materials}

We used a standard substance, PCB Mix 1 (Dr. Ehrenstorfer GmbH, Germany) with PCB Nos. 28, 52, $101,138,153$, and 180 congeners in isooctane, each at a concentration of $10 \mathrm{ng} / \mu \mathrm{l}$. Standard solutions were prepared in the range from 2.5 to $500 \mathrm{ng} / \mathrm{ml}$ by diluting in hexane. In order to find appropriate extraction conditions, certified material manufactured by RTC CRM963-50G was used. GC analytical-grade organic solvents and silver nitrate were purchased from Avantor Performance Materials (Poland). Sand required for extraction was repeatedly rinsed with distilled water and heated at $600^{\circ} \mathrm{C}$ for four hours. Silica gel for chromatographic applications, 100-200 mesh (Merck, Germany), was activated at $130^{\circ} \mathrm{C}$ for 16 hours.

\section{Soil Moisture and Organic Carbon Analysis}

Materials' moisture was checked with the use of a moisture analyzer (Sartorius MA35). Organic carbon content was determined with a total organic carbon analyzer (TOC 5000 Shimadzu).

\section{Particle Fraction}

Particle fraction was determined by test sieve in CRM963 and in candidate for the certified material of soil. Fractions were collected in the range $05-<0.025 \mathrm{~mm}$.

\section{Sample Extraction and Clean-Up}

The extraction method was based on the EPA 3545a method [11]. The ASE 100 Dionex was applied for the extraction of six PCB congeners. The soil was earlier crushed and lyophilized, and in this form delivered to laboratory. The mass of the sample was approximately $1 \mathrm{~g}$. The recovery of the method was checked for various solvents (i.e. hexane, acetone/dichloromethane in 1:1 ratio, acetone/hexane in 1:1 ratio) and for three temperature values (i.e. $120^{\circ} \mathrm{C}, 150^{\circ} \mathrm{C}, 170^{\circ} \mathrm{C}$ ). Three static cycles were performed, each held for five min. Nitrogen purge was carried out for $100 \mathrm{~s}$. The obtained extracts were concentrated to the volume of approx. $1 \mathrm{ml}$ and purified in SPE columns packed with $\mathrm{AgNO}_{3}$ silica gel. It was used hexane to elution [12]. The obtained extracts were concentrated in gentle stream of nitrogen at the temperature $50^{\circ} \mathrm{C}$ to the volume of $1 \mathrm{ml}$.

\section{PCB Analysis}

Concentrated extracts were analysed by an Agilent GC 6890N combined with an Agilent MSD 5975 in the SIM mode. The column was ZB 5MS, $30 \mathrm{~m} \times 0.25 \mathrm{~mm} \times 0.25$ $\mu \mathrm{m}$. The injector temperature was set at $265^{\circ} \mathrm{C}$, and the oven temperature started at $50^{\circ} \mathrm{C}$ (holding time one min.), increased to $150^{\circ} \mathrm{C}$ at $20^{\circ} \mathrm{C}$ per minute (holding time two minutes), then to $280^{\circ} \mathrm{C}$ at $5^{\circ} \mathrm{C}$ (holding time six min.). Helium was a carrier gas with flow of $1.1 \mathrm{ml} / \mathrm{min}$. The injecting volume was $1 \mu \mathrm{l}$. The temperature of the ion source was $300^{\circ} \mathrm{C}$.

\section{Homogeneity and Stability}

Homogeneity was calculated for five packages, each containing $50 \mathrm{~g}$ of the examined soil. Five samples were prepared from each of the packages; for each sample, three GC/MS analyses were performed. The homogeneity determination was conducted on the basis of within-the-bottle and between-bottles coefficients of variability (1). The examined analyte stability determination was based on the six PBCs' content analyses. The experience lasted four months with one month periods.

$$
C V=\frac{S D}{\bar{x}}
$$

...where: $C V$ - coefficient of variability, $S D$ - standard deviation, $\bar{x}$ - average concentration $[\mathrm{ng} / \mathrm{g}]$.

\section{Results}

\section{Water Content}

The moisture content in the CRM963 was $1.82 \%$. The examined soil was characterized by low water content ranging from $1.65 \%$ to $1.87 \%$. 
Table 1. Percentage distribution [\%] of particle fraction [mm].

\begin{tabular}{|c|c|c|c|c|c|c|c|}
\hline Material & $>0.5$ & $0.5<\mathrm{x}<0.25$ & $0.25<\mathrm{x}<0.1$ & $0.1<\mathrm{x}<0.063$ & $0.063<\mathrm{x}<0.045$ & $0.045<\mathrm{x}<0.025$ & $<0.025$ \\
\hline CRM963 & 1.28 & 7.8 & 34.9 & 19.9 & 10.7 & 13.9 & 5.9 \\
\hline Candidate for CRM & 0 & 2.2 & 48.9 & 19.8 & 10.5 & 8.8 & 5.6 \\
\hline
\end{tabular}

Table 2. Equations of calibration curves, correlation coefficients $\mathrm{R}^{2}$ and determined LOD and LOQ values of applied GC/MS system for six PCB congeners.

\begin{tabular}{|c|c|c|c|c|}
\hline Congener PCB No. & Calibration equation & $\mathrm{R}^{2}$ & LOD $[\mathrm{ng} / \mathrm{g}]$ & LOQ $[\mathrm{ng} / \mathrm{g}]$ \\
\hline 28 & $\mathrm{y}=174.25 \mathrm{x}+0.15$ & 0.9998 & 3.28 & 9.84 \\
\hline 52 & $\mathrm{y}=173.77 \mathrm{x}-27.91$ & 0.9999 & 0.82 & 2.45 \\
\hline 101 & $\mathrm{y}=170.05 \mathrm{x}-21.22$ & 0.9994 & 3.11 & 9.32 \\
\hline 153 & $\mathrm{y}=136.08 \mathrm{x}-12.68$ & 0.9995 & 8.70 & 26.09 \\
\hline 138 & $\mathrm{y}=130.43 \mathrm{x}-13.95$ & 0.9997 & 2.86 & 7.58 \\
\hline 180 & $\mathrm{y}=104.32 \mathrm{x}-88.59$ & 0.9994 & 2.62 & 7.85 \\
\hline
\end{tabular}

\section{Carbon Content}

The percentage value of carbon content in the CRM was between $0.48 \%$ and $0.72 \%$. The examined soil contained from 1.35 to $1.55 \%$ of organic carbon.

\section{Particle Fraction}

Particle fraction distribution is presented in Table 1.

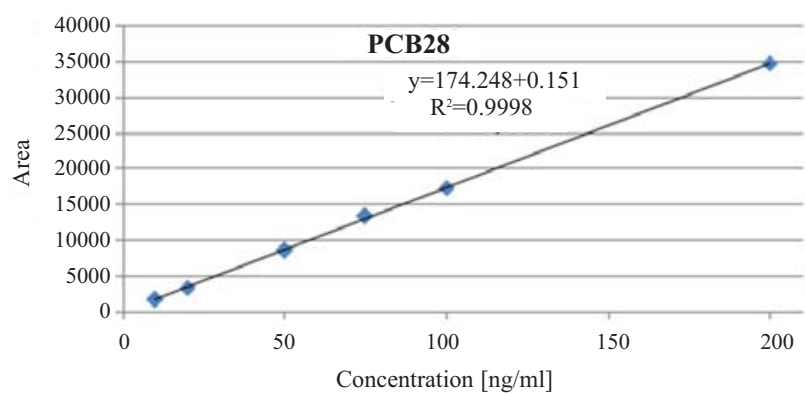

Fig. 1. Calibration curve of applied GC/MS system (SIM mode) for PCB No. 28.

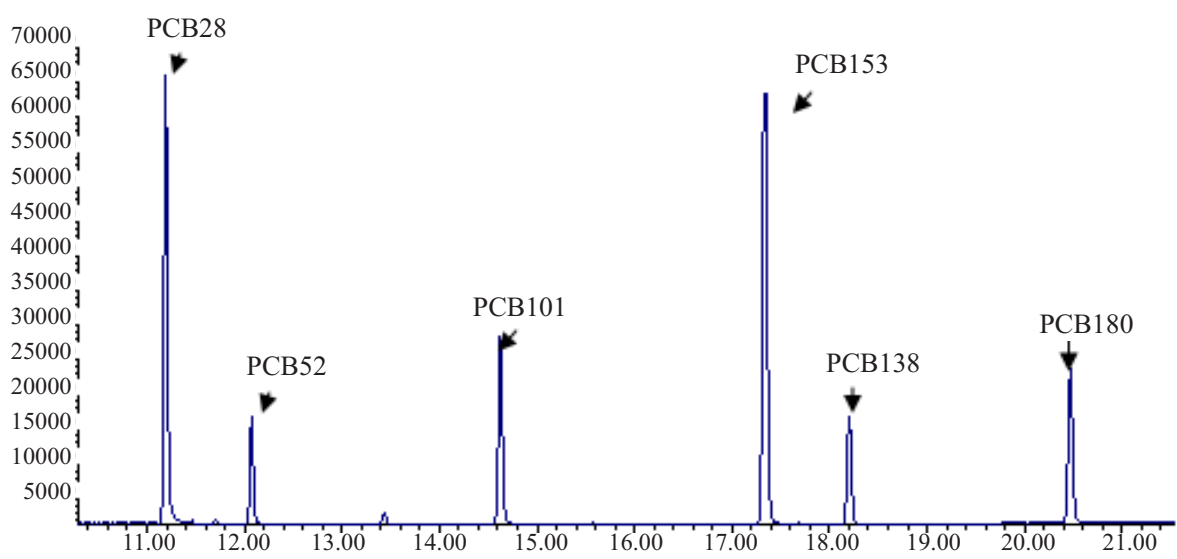

Fig. 2. Chromatogram of CRM963.

For each examined analyte, the linearity coefficients found for the calibration curves is close to 1 . Fig. 1 presents a calibration curve for PCB No. 28 and Fig. 2 presents a chromatogram obtained from the CRM963 analysis. Based on equations, the detection and quantification limits of six PCB congeners were calculated. The values of the abovementioned parameters are presented in Table 2. Jurowski et al. [13] described how an important step in method validation is calibration.

On the basis of the analyses carried out and certified values, the recovery value for each particular analyte was found (Table 3). Both recovery as well as standard deviation values are essential when choosing the most efficient method conditions.

\section{Homogeneity and Stability}

In order to analyse soil that was a candidate for the certified material, hexane was applied as the solvent. The extraction was carried out at $170^{\circ} \mathrm{C}$. The choice was 
Table 3. Contents of PCB congeners in certification of CRM963, recoveries (Recov.) and standard deviations (SD) [\%] for used conditions of method.

\begin{tabular}{|c|c|c|c|c|c|c|c|c|c|c|c|c|c|}
\hline \multicolumn{2}{|c|}{ PCB } & \multicolumn{2}{|c|}{ No. 28} & \multicolumn{2}{|c|}{ No. 52} & \multicolumn{2}{|c|}{ No. 101} & \multicolumn{2}{|c|}{ No. 153} & \multicolumn{2}{|c|}{ No. 138} & \multicolumn{2}{|c|}{ No. 180} \\
\hline \multicolumn{2}{|c|}{ Certified contents[ng/g] } & \multicolumn{2}{|c|}{$148 \pm 25.5$} & \multicolumn{2}{|c|}{$40.3 \pm 3.26$} & \multicolumn{2}{|c|}{$77.3 \pm 11.3$} & \multicolumn{2}{|c|}{$290 \pm 28.1$} & \multicolumn{2}{|c|}{$84.5 \pm 3.98$} & \multicolumn{2}{|c|}{$135 \pm 20.0$} \\
\hline Solvent & Temp. $\left[{ }^{\circ} \mathrm{C}\right]$ & Recov. & SD & Recov. & SD & Recov. & SD & Recov. & SD & Recov. & SD & Recov. & SD \\
\hline \multirow{2}{*}{ Hexnae } & 150 & 91.3 & 7.1 & 102.1 & 9.1 & 96.0 & 4.2 & 102.4 & 3.8 & 92.0 & 2.7 & 110.1 & 2.3 \\
\hline & 170 & 90.4 & 3.6 & 99.0 & 5.7 & 94.3 & 4.6 & 99.9 & 5.3 & 88.5 & 4.0 & 106.0 & 2.1 \\
\hline \multirow{2}{*}{$\begin{array}{c}\text { Hexane/ } \\
\text { Acetone }(1: 1)\end{array}$} & 150 & 91.3 & 10.5 & 84.5 & 6.7 & 88.9 & 0.3 & 96.7 & 1.8 & 82.2 & 5.5 & 114.9 & 14.3 \\
\hline & 170 & 95.0 & 10.1 & 94.3 & 7.7 & 105.3 & 3.6 & 117.2 & 2.8 & 104.6 & 0.8 & 138.5 & 17.7 \\
\hline \multirow{2}{*}{$\begin{array}{l}\text { Acetone/ } \\
\text { DCM (1:1) }\end{array}$} & 150 & 109.8 & 13.7 & 104.3 & 8.0 & 115.4 & 12.0 & 124.3 & 12.4 & 115.1 & 13.4 & 145.9 & 8.4 \\
\hline & 170 & 96.6 & 3.7 & 102.7 & 3.1 & 106.6 & 2.7 & 118.5 & 4.4 & 109.2 & 8.7 & 142.6 & 10.4 \\
\hline
\end{tabular}
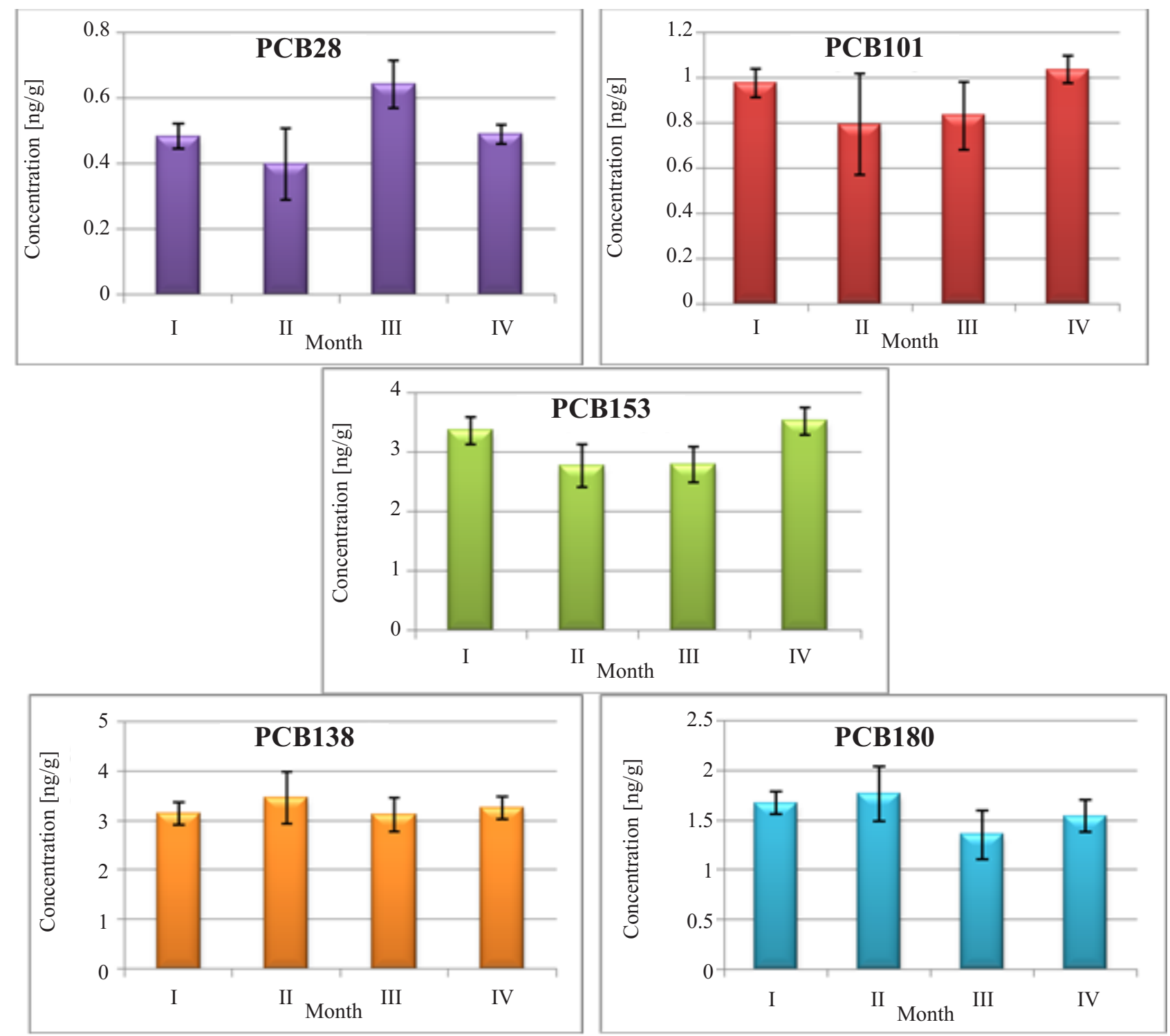

Fig. 3. Comparison of concentration congeners of PCBs over four months. 
Table 4. Coefficients of variability within-the-bottle $\mathrm{CV}_{\mathrm{WB}}$ and between-bottles $\mathrm{CV}_{\mathrm{BB}}$.

\begin{tabular}{|c|c|c|}
\hline Congener of PCB & $\mathrm{CV}_{\mathrm{WB}}[\%]$ & $\mathrm{CV}_{\mathrm{BB}}[\%]$ \\
\hline No. 28 & 49.0 & 14.9 \\
\hline No. 52 & $\mathrm{ND}$ & $\mathrm{ND}$ \\
\hline No. 101 & 45.4 & 34.4 \\
\hline No. 153 & 41.6 & 18.4 \\
\hline No. 138 & 34.7 & 32.8 \\
\hline No. 180 & 40.8 & 47.0 \\
\hline
\end{tabular}

ND - not detected

justified by high recovery values and lowest standard deviations obtained for each of the analytes examined. With regard to low content levels of particular congeners, it was necessary to increase the weighed amount to $1.5 \mathrm{~g}$ and concentrate the sample to the volume of $100 \mu \mathrm{l}$. PCB No. 52 was not detected. Coefficient of variability values are presented in Table 4.

Fig. 3 shows charts comparing the analyze contents in one of the five packages examined within four months. As can be seen from the charts, there is no decrease in PCB congener concentrations. The analyze content is constant; standard deviations are on a comparable level.

\section{Results and Discussion}

The levels of both moisture and organic carbon were at comparable levels in the cases of the environmental matrices examined. Particle fractions were also similar. Therefore, the choice of the CRM to study the method conditions was confirmed to be suitable for the determination of PCBs in soil. The method was further used to separate six PCB congeners from the soil being the candidate for the reference material. The linearity, detection, and quantification limits - as well as recovery and repeatability calculations performed - allowed us to find the most efficient method conditions. Hexane was applied as the solvent and the temperature was set at $170^{\circ} \mathrm{C}$ due to the recovery values close to $100 \%$ and ranging from 80 to $120 \%$, which is required for the analytical method. Also, the standard deviation values were lower than $10 \%$ for each of the analytes.

In the case of soil being a candidate for reference material, it was found that the total amount of the analytes examined does not exceed $20 \mathrm{ng} / \mathrm{g}$. The values of the $\mathrm{CV}$ which were calculated in order to determine the homogeneity within-the-bottle and between-bottles are 34.7-55.4\% and 14.9$47 \%$, respectively. It is necessary to take these values into account when estimating the uncertainty of the certified values. The comparison of the analytes contents examined every month for four consecutive months shows that these values undergo no changes. Thus it can be stated that, in terms of the PCB congeners, the material content is stable.

\section{Acknowledgements}

This project is supported by National Center for Research and Development, No. INNOTECH-K1/IN1/43/ 158947/NCBR/12 (MODAS).

The authors are grateful for financial support from European Regional Development Fund under the ROP for the years 2007-2013: project No. RPKP.05.04.00-04-003/13.

\section{References}

1. UNEP, Stockholm Convention on Persistent Organic Pollutants UNEP Doc., UNEP/POPS/CONF/2, 2001.

2. LI Y., LIU L., ZHANG Z., REN N., JIA H., MA J., SVARKO E. Polychlorinated Biphenyls in Global Air and Surface Soil: Distributions, Air-Soil Exchange, and Fractionation Effect. Environ. Sci. Technol. 44, 2784, 2010.

3. PO-ON TANG H. Recent development in analysis of persistent organic pollutants under the Stockholm Convention. Trac-Trend. Anal. Chem. 45, 48, 2013.

4. INTERNATIONAL ORGANIZATION FOR STANDARDIZATION (Geneva, Switzerland) Quality system gudelines for the production of reference materials, ISO/IEC Guide 34, 1996; Terms and definitions used in connection with reference materials, ISO Guide 30, 1992; Contents of certificates of reference materials, ISO Guide 31, 1981; Certification of reference materials: general and statistical principles, ISO/IEC Guide 35, 1989; Calibration in analytical chemistry and use of certified reference materials, ISO Guide 32, 1997; Uses of Certified Reference Materials, Revised ISO Guide 33, 2000.

5. KUPIEC K., KONIECZKA P., NAMIEŚNIK J. Prospects for the production, research and utilization of reference materials. Crit. Rev. Anal. Chem. 39, 311, 2009.

6. CHEN Y.Q., LI Y., TOMS L.M., GALLEN M., HEARN L., SLY P.D., MUELLER J.F. A preliminary study on assessing body burden of persistent orgainic pollutants (pops) in infants through analysis of faeces. Organohalogen Compound 75, 1193, 2013.

7. OTTONELLO G., FERRARI A., MAGI E. Determination of polychlorinated biphenyls in fish: Optimisation and validation of a method based on accelerated solvent extraction and gas chromatography-mass spectrometry. Food Chem 142, 327, 2014.

8. GE J., WOODWARD L.A., LI Q.X., WANG J. Distribution, sources and risk assessment of polychlorinated biphenyls in soils from the midway atoll, north pacific ocean. PLoS ONE, 8, (8), 2013.

9. BEYER A., BIZIUK M. Applications of sample preparation techniques in the analysis of pesticides and PCBs in food. Food Chem 108, 669, 2008.

10. DAI S.-H., ZHAO H.-L., WANG M., WONG C.S., CHAI T.-T., YANG S.-M., QIU J. Determination of polychlorinated biphenyl enantiomers in lotus root and sediment by chiral gas chromatography-mass spectrometry. Chinese J. Anal. Chem. 40, 1758, 2012.

11. SW-846 Method EPA 3545a: Pressured Fluid Extraction (PFE). U.S. Environmental Protection Agency, February, 2007.

12. EN 16167 Sludge, treated biowaste and soil - Determination of polychlorinated biphenyls (PCB) by gas chromatography with mass selective detection (GC-MS) and gas chromatography with electron-capture detection (GC-ECD), 2012.

13. JUROWSKI K., BUSZEWSKI B., PIEKOSZEWSKI W. The analytical calibration in (bio)imaging/mapping of the metallic elements in biological samples - definitions, nomenclature and strategies: state of the art. Talanta 131, 273, 2015. 
